\title{
Genes related to inherited microphthalmia and anophthalmia
}

\author{
Diana Matías-Pérez ${ }^{1,2}$, Iván Antonio García-Montalvo and Juan Carlos Zenteno ${ }^{3,4}$ \\ ${ }^{1}$ Biochemistry and Immunology Unit ITO-UNAM; ${ }^{2}$ Research Center UNAM-UABJO, Oaxaca, Oax.; ${ }^{3}$ Department of Biochemistry, Faculty of Medicine, \\ Universidad Nacional Autónoma de México; ${ }^{4}$ Instituto de Oftalmología Conde de Valenciana, Ciudad de México, Mexico
}

\begin{abstract}
Congenital eye malformations are the second most common cause of childhood blindness and are originated by disruption of the normal process of eye development during embryonic stage. Their etiology is variable, although monogenic causes are of great importance as they have a high risk of familial recurrence. Included among the most severe congenital eye abnormalities are microphthalmia, defined by an abnormally small eye, and anophthalmia, characterized by congenital absence of ocular structures. The current knowledge of the genes involved in human microphthalmia and anophthalmia in humans is revised in this work.
\end{abstract}

KEY WORDS: Microphthalmia. Anophthalmia. Eye development. Congenital eye malformation. Genes.

\section{Congenital eye malformations}

Alteration or disruption of any of the numerous processes involved in early development of the eye in humans originate a broad spectrum of congenital eye malformations. Although eye malformations can occur as part of complex genetic syndromes, frequently they are observed in isolation, indicating the disruption of a development process that is exclusive to the ey $\mathrm{e}^{1,2}$. On the other hand, the degree of visual impairment associated with these anomalies is variable and depends on the seriousness of the malformation. The etiology of these malformations is complex and can include environmental or genetic factors or a combination of both. Environmental causes can correspond to chemical, biological or physical teratogenic agents that interrupt eye normal development ${ }^{3}$. Genetic factors associated with malformations can be of three types: multifactorial, chromosomal and monogenic. The most common congenital eye malformation etiology is considered to be the multifactorial one, where the combination of numerous variants in different genes with environmental-type factors is synergistic to originate the malformation. In general, multifactorial and chromosomal alterations have low risk if being inherited by the offspring. The monogenic etiology (also called Mendelian) refers to diseases caused by mutation in a single gene. In these cases there is high risk of repetition in relatives of an affected individual ${ }^{4,5}$. Monogenic etiology eye malformations are transmitted to the offspring with autosomal dominant, autosomal recessive. X-linked recessive or X-linked dominant patterns. Congenital eye malformations with higher clinical repercussion include microphthalmia and anophthalmia ${ }^{1,6}$.

\section{Microphthalmia}

Microphthalmia is defined as an eye with an axial length two standard deviations below average-for-age, measured by ultrasound ${ }^{7}$. Microphthalmia can occur unilaterally or bilaterally, and in the unilateral cases, the compromised side of the face is generally less developed and the orbit is small (Fig. 1).

Microphthalmia can be associated with other ocular or extraocular congenital anomalies. Some cases of microphthalmia can be associated with an eye cyst

\section{Correspondence:}

Juan Carlos Zenteno

Chimalpopoca, 14

Col. Obrera

C.P. 06800 , Ciudad de México, México

E-mail: jczenteno@institutodeoftalmología.org
Date of reception: 10-05-2016

Date of acceptance: 03-06-2016

DOI://dx.doi.org/10.24875/GMM.M18000089
Gac Med Mex. 2017;153:746-751

Contents available at PubMed www.gacetamedicademexico.com 


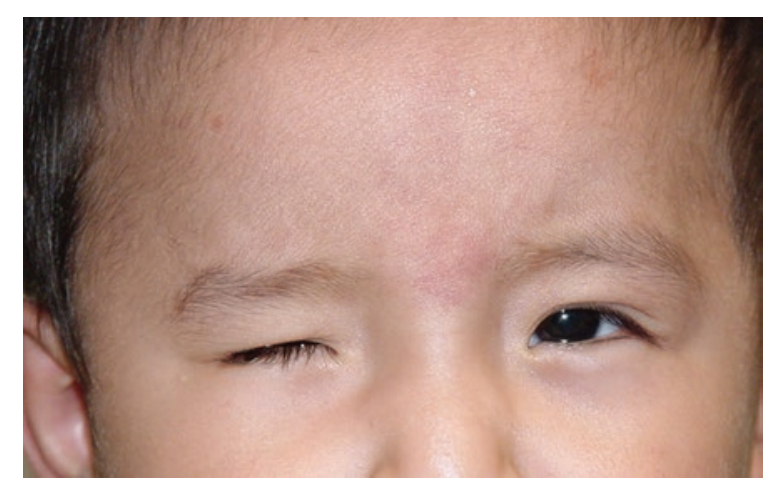

Figure 1. Patient with microphthalmia (courtesy of Dr. Óscar Francisco Chacón).

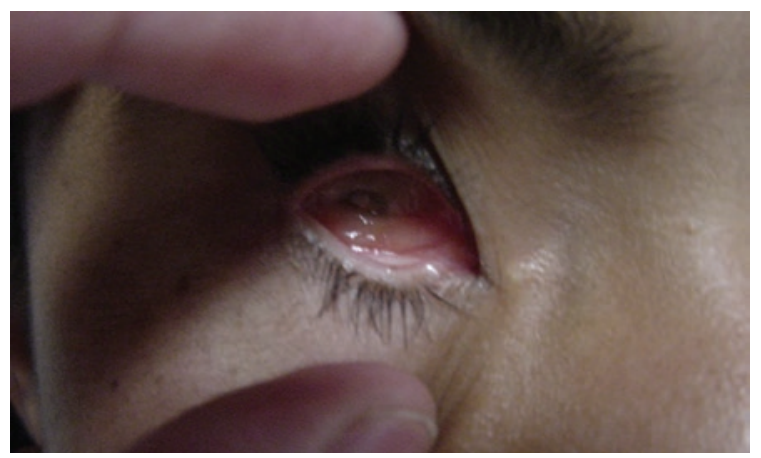

Figure 2. Patient with anophthalmia (courtesy of Dr. Óscar Francisco Chacón).

(cystic microphthalmia), which is thought to be the result of a failure in optic fissure closure ${ }^{7-10}$.

\section{Anophthalmia}

The most serious eye malformation is anophthalmia, which is defined by the absence of the eye globe with preservation of the ocular appendages (eyelids and lacrimal ducts) (Fig. 2). In some cases, recognizing ocular tissue is possible only from the histological point of view ${ }^{11}$. In primary anophthalmia, prosencephalon development is suppressed, which results in the absence of one or both eyes, whereas in secondary anophthalmia, the development of the eye is interrupted at the beginning of the fourth week and it is due to a failure in the formation of the lens vesicle $e^{12,13}$.

\section{Genes implicated in the development of microphthalmia and anophthalmia}

In the past few years, different genes whose mutations are the cause of a broad spectrum of eye malformations in humans have been identified ${ }^{14,15}$. Mutations in these genes have been found to explain from 18 to $25 \%$ of microphthalmia and anophthalmia cases.
Table 1. Genes related to the development of microphthalmia and anophthalmia

\begin{tabular}{ll}
\hline Eye malformation & Related genes \\
\hline Microphthalmia & $\begin{array}{l}\text { SOX2, SIX3, OTX2, RAX, CHX10, GDF6, FOXE3, } \\
\text { GDF3, STRA6 }\end{array}$ \\
Anophthalmia & ALDH1A3, ATOH7, RARB and PAX6 \\
\hline
\end{tabular}

Table 2. Localization of genes implicated in anophthalmia and microphthalmia

\begin{tabular}{lcl}
\hline Gene & Locus (location) & Human ocular phenotype \\
\hline SOX2 & $3 q 26.3-q 27$ & Anophthalmia/microphthalmia \\
OTX2 & $14 q 22$ & Anophthalmia/microphthalmia \\
RAX & $18 q 21.3$ & Anophthalmia/microphthalmia \\
SIX3 & $2 p 21$ & Anophthalmia/microphthalmia \\
STRA6 & $15 q 24.1$ & Anophthalmia \\
ALDH1A3 & $15 q 26$ & Microphthalmia \\
ATOH7 & $10 q 22.2$ & Microphthalmia \\
RARB & $3 p 24$ & Anophthalmia/microphthalmia \\
PAX6 & $11 p 13$ & Anophthalmia/microphthalmia \\
CHX10 & $14 q 24.3$ & Microphthalmia \\
GDF6 & $8 q 22$ & Microphthalmia \\
FOXE3 & $1 p 32$ & Microphthalmia \\
GDF3 & $12 p 13$ & Microphthalmia \\
\hline
\end{tabular}

In the following sections, the most important features of these genes are described (Tables 1 and 2).

\section{SOX2}

SOX2, localized in chromosome $3 q 26$, is the most important gene of this group, since its mutations are estimated to be the cause of approximately 10 to $20 \%$ of anophthalmia mas bilateral microphthalmia cases $^{16,17}$. SOX2 encodes a transcription factor with an essential function in embryonic development in numerous tissues, including the eye and the brain. It acts cooperatively with $P A X 6$ to regulate other genes that promote the development of the lens ${ }^{16,18}$, and different dominant mutations of this gene have been described in subjects with anophthalmia or microphthalmia, including point mutations and complete or partial deletions ${ }^{19}$. One of the mutations most commonly identified and that corresponds to a deletion of 20 bases at the 5 ' extreme of the gene was initially described in Mexican patients with anophthalmia ${ }^{20-22}$. Some patients with mutation in SOX2 develop the so-called SOX 
deficiency syndrome, which, in addition to eye malformations, includes intellectual impairment, neurological anomalies, facial dysmorphias, postnatal growth retardation, esophageal anomalies and cryptorchidism ${ }^{23,24}$.

\section{OTX2}

The OTX2 gene, located at 14q22, encodes a transcription factor that is necessary for cephalic structures embryonic development in vertebrates ${ }^{21}$. Different dominant mutations have been described in this gene in patients with anophthalmia or microphthalmia associated with central nervous system malformations and intellectual disability ${ }^{25,28}$, although cases with retinal dysplasia have been identified as well ${ }^{29}$. Approximately $3 \%$ of anophthalmia/midrophthalmia cases are due to mutations in OTX214.

\section{RAX}

$R A X$, located at $18 \mathrm{q} 21.32$, is another essential gene for ocular development, possibly due to its function in the establishment and proliferation of retinal progenitor cells ${ }^{30}$. Around $2 \%$ of subjects with anophthalmia or microphthalmia carry mutations in $R A X^{31,32}$. Unlike the previously mentioned genes, $R A X$ gene mutations follow an autosomal recessive inheritance pattern.

\section{SIX3}

The $S I X 3$ gene is located at $2 p 21$ and is crucial in embryonic development, since it intervenes in the anterior brain and eye formation. It encodes a protein with transcription factor function that binds to DNA specific sequences and represses Wnt1 gene activity, an event that ensures normal cerebral development in mammals ${ }^{33}$. By blocking Wnt1 gene activity, SIX3 is able to prevent hindbrain abnormal expansion in the forebrain zone. During retinal development, SIX3 has been shown to have a key function in PAX6 activation to promote the lens development ${ }^{34,35}$. In addition, SIX3 plays a strategic role in SOX2 activation ${ }^{36}$. Mutations in SIX3 also cause serious cerebral malformations, such as type 2 holoprosencephaly (HPE2) ${ }^{37}$, In HPE2, the brain is unable to separate in two hemispheres during early embryonic development, which drives to eye malformations (including cyclopia) and serious facial abnormalities ${ }^{38}$. Mutations in the SIX3 gene follow an autosomal recessive inheritance pattern.

\section{STRA6}

STRA6 (a retinoic acid-stimulated gene) encodes a protein of the same name that acts as a cell receptor to capture end transport retinol to specific tissues, mainly the ey ${ }^{39,40}$. STRA6 is located in chromosome $15 q 24.1$, and its mutations originate anophthalmia, heart defects, pulmonary hypoplasia and diaphragmatic hernia ${ }^{41,42}$, which indicates the importance of this gene in normal embryonic development.

\section{ALDH1A3}

ALDH1A3 encodes aldehyde dehydrogenase $1 \mathrm{~A} 3$ isoform, which is involved in the synthesis of retinoic acid through retinaldehyde oxidation and thus it has an essential function during the eye's early development ${ }^{43}$. The ALDH1A3 gene is located at chromosome $15 q 26.3$ and, recently, its mutations have been shown to be the cause of autosomal recessive inheritance microphthalmia and anophthalmia ${ }^{44,45}$.

\section{ATOH7}

The ATOH7 gene (atonal 7 homologous) encodes a helix-loop-helix-type protein and plays an important role in retinal ganglion cell subsets differentiation ${ }^{46}$. ATOH7 is located at $10 \mathrm{q} 21.3^{47}$, and mutations have been recently identified in patients with microphthalmia and other eye development anomalies, such as persistent hyperplastic primary vitreous ${ }^{48,49}$.

\section{RARB}

The retinoic acid receptor beta gene $(R A R B)$ is a member of the thyroid and steroid hormone nuclear receptors superfamily. The RARB protein binds to retinoic acid, which acts as a cell signaling intermediary in embryonic morphogenesis, cell growth and ocular differentiation processes ${ }^{50}$. Recently, using a whole exome sequencing approach, different mutations in this gene were identified in subjects with unilateral or bilateral microphthalmia ${ }^{51}$.

\section{PAX6}

PAX6 is known as a "master gene" of eye development, since it intervenes at early and final stages of ocular morphogenesis, neural differentiation and synaptic connections configuration ${ }^{52,53}$. PAX6 is located 
at chromosome $11 \mathrm{p} 13^{54,55}$, and is widely expressed in the optic vesicle, the lens, the retina and the cornea during ocular development ${ }^{56-58}$. Typically, PAX6 mutations cause bilateral aniridia ${ }^{59,60}$, although certain mutations have also been associated with a broader spectrum of ocular and cerebral defects ${ }^{60}$. Cases of anophthalmia have been identified with mutations in $P A X 6^{60-62}$.

\section{VSX2}

This gene, also known as $\mathrm{CHX10}$, is located at $14 q 24$ and encodes a protein that enables the proliferation of neuroretinal precursor cells ${ }^{63}$. The eye phenotype associated with VSX2 mutations is heterogeneous, since cases of microphthalmia, coloboma or cataracts have been described ${ }^{64-66}$. Approximately $2 \%$ of subjects with microphthalmia exhibit recessive mutations in $V S X 2^{64}$. However, in a recent study in 50 Mexican subjects with anophthalmia or microphthalmia, no mutations were identified in this gene ${ }^{32}$, which indicates that there are ethnic variations in the mutational frequencies of genes associated with eye malformations.

\section{GDF6}

GDF6, located at $8 q 22$, encodes a member of the bone morphogenic proteins family, and is the cause of up to $8 \%$ of congenital eye malformation cases, in particular microphthalmia and coloboma ${ }^{32,67}$. In addition to eye malformations, some patients with dominant mutations in this gene show skeletal alterations and polydactyly, which indicates the importance of GDF6 gene in different aspects of early embryonic develolpment ${ }^{68}$.

\section{FOXE3}

The FOXE3 gene, located at 1p32, encodes an eye development-specific transcription factor that is highly preserved in phylogeny. Mutations in FOXE3originate a broad spectrum of eye malformations, including anterior sector anomalies, congenital aphakia, sclerocornea, cataracts and microphthalmia ${ }^{69-72}$. In a recent study, approximately $25 \%$ of subjects with microphthalmia had recessive mutations in FOXE3 $3^{71}$. One interesting aspect of this gene is that its heterozygous (dominant) mutations have been also associated with eye anomalies, such as chorioretinal and iris colobomas,
Peters' anomaly and early-onset cataracts. In an analysis of 236 subjects with developmental eye anomalies, two new heterozygous mutations of FOXE3 were identified, which dominantly segregated into two different families $^{73}$. By means of in situ hybridization in human embryos, FOXE3 expression was shown to be exclusive of the eye, mainly in the anterior segment, which suggests that the extralenticular phenotypes caused by mutations in FOXE3 are probably secondary to the formation of abnormal lenses ${ }^{15,72}$.

\section{GDF3}

GDF3 is a gene located at 12p13.1 that codifies a protein belonging to the bone morphogenic proteins family, which participate in a wide variety of processes during embryonic development ${ }^{73}$. In a group of 33 patients with eye malformations, four cases with dominant mutations in GDF3 and a broad spectrum of eye malformations, ranging from iris coloboma to bilateral microphthalmia, were identified ${ }^{74}$. Interestingly, evidence was found of lack of penetrance of some of these mutations ${ }^{15,74}$. GDF3 has been estimated to be mutated in approximately $2 \%$ of patients with the microphthalmia-anophthalmia-coloboma and thus should be included as one of the genes to be analyzed in subjects with congenital eye malformations.

\section{Final considerations}

In the past few years, genes whose mutations originate a broad spectrum of eye malformations in the human being have been identified. Subsequently, functional, expression and animal model studies have confirmed the participation of these genes in the pathways of eye normal development ${ }^{75,76}$. Availability of new technologies, such as whole genome sequencing and whole exome sequencing, have significantly increased the capability to identify new genes related to this type of inherited anomalies. In addition to establishing the malformation specific cause, which is information that is highly valuable to the patient and his/her family, one of the goals of the genetic studies in patients with eye malformations is to estimate the mutation frequency of each gene in specific ethnic groups. This information is highly relevant for genotyping better planning in new cases, to better understanding these malformations' physiopathogenesis and for adequate genetic counseling of affected subjects' families. 


\section{Authors' contributions}

IAGM participated in the concept and design of the study, as well as in the writing and critical review of the manuscript. JCZ participated in the design and in the critical review of the manuscript.

\section{References}

1. Reis LM, Semina EV. Conserved genetic pathways associated with microphthalmia, anophthalmia, and coloboma. Birth Defects Res C Embryo Today. 2015;105:96-113.

2. Adams DJ, Clark DA. Common genetic and epigenetic syndromes. Pediatr Clin North Am. 2015;62:411-26.

3. Lagutin OV, Zhu CC, Kobayashi D, et al. SIX3 repression of Wnt signaling in the anterior neuroectoderm is essential for vertebrate forebrain development. Genes Dev. 2003;17:368-79.

4. Källén B, Robert $E$, Harris J. The descriptive epidemiology of anophthalmia and microphthalmia. Int J Epidemiol. 1996;25:1009-16.

5. Mihelec M, StHeaps L, Flaherty M, et al. Chromosomal rearrangements and novel genes in disorders of eye development, cataract and glaucoma. Twin Res Hum Genet. 2008;11:412-21.

6. Diomande IA, Toure A, Koffi KV, et al. Anophthalmia and serious microphthalmia: a summary of the problems associated with antenatal diagnosis and therapeutic refunding in Sub-Saharan Africa. Int Med Case Rep J. 2015;8:287-90.

7. Morrison D, FitzPatrick D, Hanson I, et al. National study of microphthalmia, anophthalmia, and coloboma (MAC) in Scotland: investigation of genetic aetiology. J Med Genet. 2002;39:16-22.

8. Schittkowski M, Hingst V, Knaape A, et al. Orbital volume in congenital clinical anophthalmos. Klin Monbl Augenheilkd. 2004;221:898-903.

9. Fitzpatrick DR, Van Heyningen V. Developmental eye disorders. Curr Opin Genet Dev. 2005;15:348-53.

10. Dolk H, Busby A, Armstrong BG, et al. Geographical variation in anophtalmia and microphtalmia in England, 1988-94. BMJ. 1998:317:905-10.

11. Navas-Aparicio MC, Hernández-Carmona SJ. Anoftalmía y microftalmía: descripción, diagnóstico y conducta de tratamiento. Revisión bibliográfica. Rev Mex Oftalmol. 2008;82:205-9.

12. Albernaz VS, Castillo M, Hudgins PA, et al. Imaging findings in patients with clinical anophthalmos. AJNR Am J Neuroradiol. 1997:18:555-61.

13. Bardakjian TM, Schneider A. The genetics of anophthalmia and microphthalmia. Curr Opin Ophthalmol. 2011;22:309-13.

14. Bakrania $P$, Robinson DO, Bunyan DJ, et al. SOX2 anophthalmia syndrome: 12 new cases demonstrating broader phenotype and high frequency of large gene deletions. Br J Ophthalmol. 2007;91:1471-6.

15. García-Montalvo IA, Zenteno JC. Genetic basis of severe congenital eye defects. Rev Mex Oftalmol. 2013;87:64-9.

16. Schneider A, Bardakjian T, Reis LM, et al. Novel SOX2 mutations and genotype-phenotype correlation in anophthalmia and microphthalmia. Am J Med Genet A. 2009;149:2706-15.

17. Chassaing N, Causse A, Vigouroux A, et al. Molecular findings and clinical data in a cohort of 150 patients with anophthalmia/microphthalmia. Clin Genet. 2014:86:326-34.

18. Inoue M, Kamachi $\mathrm{Y}$, Matsunami $\mathrm{H}$, et al. PAX6 and SOX2-dependent regulation of the Sox2 enhancer N-3 involved in embryonic visual system development. Genes Cells. 2007;12:1049-61.

19. Fantes J, Ragge NK, Lynch S, et al. Mutations in SOX2 cause anophthalmia. Nat Genet. 2003;33:461-3

20. Zenteno JC, Gascon-Guzman G, Tovilla-Canales JL. Bilateral anophthalmia and brain malformations caused by a $20-b p$ deletion in the SOX2 gene. Clin Genet. 2005;68:564-6.

21. Zenteno JC, Pérez-Cano HJ, Aguinaga M. Anophthalmia-esophageal atresia syndrome caused by an SOX2 gene deletion in monozygotic twin brothers with markedly discordant phenotypes. Am J Med Genet A. 2006;140:1899-903.

22. Reis LM, Tyler RC, Schneider A, et al. Examination of SOX2 in variable ocular conditions identifies a recurrent deletion in microphthalmia and lack of mutations in other phenotypes. Mol Vis. 2010;28:768-73.

23. Ragge NK, Lorenz B, Schneider A, et al. SOX2 anophthalmia syndrome. Am J Med Genet A. 2005:135:1-7.

24. Williamson KA, Hever AM, Rainger J, et al. Mutations in SOX2 cause anophthalmia-esophageal-genital (AEG) syndrome. Hum Mol Genet. 2006;15:1413-22.

25. Ragge NK, Brown AG, Poloschek CM, et al. Heterozygous mutations of OTX2 cause severe ocular malformations. Am J Hum Genet. 2005;76:1008-22.

26. Wyatt A, Bakrania P, Bunyan DJ, et al. Novel heterozygous OTX2 mutations and whole gene deletions in anophthalmia, microphthalmia and coloboma. Hum Mutat. 2008;29:278-83.
27. Schilter KF, Schneider A, Bardakjian T, et al. OTX2 microphthalmia syndrome: four novel mutations and delineation of a phenotype. Clin Genet. 2011;79:158-68.

28. Henderson $\mathrm{RH}$, Williamson KA, Kennedy JS, et al. A rare de novo nonsense mutation in OTX2 causes early onset retinal dystrophy and pitutary dysfunction. Mol Vis. 2009;15:2442-7.

29. Bailey TJ, El-Hodiri H, Zhang L, et al. Regulation of vertebrate eye development by $\mathrm{Rx}$ genes. Int J Dev Biol. 2004;48:761-70.

30. Voronina VA, Kozhemyakina EA, O'Kernick CM, et al. Mutations in the human RAX homeobox gene in a patient with anophthalmia and sclerocornea. Hum Mol Genet. 2004;13:315-22.

31. Lequeux L, Rio M, Vigouroux A, et al. Confirmation of RAX gene involvement in human anophthalmia. Clin Genet. 2008;74:392-5.

32. González-Rodríguez J, Pelcastre EL, Tovilla-Canales JL, et al. Mutational screening of CHX10, GDF6, OTX2, RAX and SOX2 genes in 50 unrelated microphthalmia-anophthalmia-coloboma (MAC) spectrum cases. Br J Ophthalmol. 2010;94:1100-4.

33. Samuel A, Rubinstein AM, Azar TT, et al. Six3 regulates optic nerve development via multiple mechanisms. Sci Rep. 2016;6:1-14.

34. Anand D, Lachke SA. Systems biology of lens development: a paradigm for disease gene discovery in the eye. Exp Eye Res. 2016;S00144835(16):30040-9.

35. Avdonin PP, Markitantova IV, Zinov'eva RD, et al. Expression of regulatory genes Pax6, Otx2, Six3, and FGF2 during newt retina regeneration. Izv Akad Nauk Ser Biol. 2008;4:414-21.

36. Slavotinek AM. Eye development genes and known syndromes. Mol Genet Metab. 2011;104:448-56.

37. Granadino B, Gallardo ME, López-Rios J, et al. Genomic cloning, structure, expression pattern, and chromosomal location of the human SIX3 gene. Genomics. 1999;55:100-5.

38. Wallis DE, Roessler E, Hehr U, et al. Mutations in the homeodomain of the human SIX3 gene cause holoprosencephaly. Nat Genet. 1999; 22:196-8.

39. Kawaguchi R, Yu J, Honda J, et al. A membrane receptor for retinol binding protein mediates cellular uptake of vitamin A. Science. 2007; 315:820-5.

40. West B, Bove KE, Slavotinek AM. Two novel STRA6 mutations in a patient with anophthalmia and diaphragmatic eventration. Am J Med Genet A 2009:149A:539-42.

41. Slavotinek AM, García ST, Chandratillake G, et al. Exome sequencing in 32 patients with anophthalmia/microphthalmia and developmental eye defects. Clin Genet. 2015;88:468-73.

42. Segel R, Levy-Lahad E, Pasutto F, et al. Pulmonary hypoplasia-diaphragmatic hernia-anophthalmia-cardiac defect (PDAC) syndrome due to STRA6 mutations - what are the minimal criteria? Am J Med Genet A. 2009:149:2457-63.

43. Petrosino JM, Disilvestro D, Ziouzenkova O. Aldehyde dehydrogenase 1A1: friend or foe to female metabolism? Nutrients. 2014:6:950-73.

44. Fares-Taie L, Gerber S, Chassaing N. ALDH1A3 mutations cause recessive anophtalmia and microphtalmia. Am J Hum Genet. 2013; 92:265-70.

45. Grün F, Hirose $Y$, Kawauchi S, et al. Aldehyde dehydrogenase 6, a cytosolic retinaldehyde dehydrogenase prominently expressed in sensory neuro-epithelia during development. J Biol Chem. 2000;275:41210-8.

46. Huang $\mathrm{C}$, Chan JA, Schuurmans C. Proneural bHLH genes in development and disease. Curr Top Dev Biol. 2014:110:75-127.

47. Brown N. Ganglion cell development: early steps/fate. The retina and its disorders. Elsevier; 2010. p. 235-40.

48. Khan K, Logan $C$, McKibbin M, et al. Next generation sequencing identifies mutations in Atonal homolog 7 (ATOH7) in families with global eye developmental defects. Hum Mol Gen. 2012;21:776-83.

49. Prasov L, Masud T, Khaliq S, et al. ATOH7 mutations cause autosomal recessive persistent hyperplasia of the primary vitreous. Hum Mol Genet. 2012;21:3681-94.

50. Williamson KA, FitzPatrick DR. The genetic architecture of microphthalmia, anophthalmia and coloboma. Eur J Med Genet. 2014:57:369-80.

51. Srour M, Chitayat D, Caron V, et al. Recessive and dominant mutations in retinoic acid receptor beta in cases with microphthalmia and diaphragmatic hernia. Am J Hum Genet. 2013:93:765-72.

52. Shaham O, Menuchin Y, Farhy C, et al. Pax6: a multi-level regulator of ocular development. Prog Retin Eye Res. 2012;31:351-76.

53. Erclik T, Hartenstein V, Mclnnes RR, et al. Eye evolution at high resolution: the neuron as a unit of homology. Dev Biol. 2009;332:70-9.

54. Okladnova O, Syagailo YV, Mössner R, et al. Regulation of PAX6 gene transcription: alternate promoter usage in human brain. Mol Brain Res. 1998:60:177-92.

55. Williams SC, Altmann CR, Chow RL, et al. A highly conserved lens transcriptional control element from the PAX6 gene. Mech Dev. 1998;73:225-9.

56. Jordan T, Hanson I, Zaletayev D, et al. The human PAX6 gene is mutated in two patients with aniridia. Nat Genet. 1992;1:328-32.

57. Cvekl A, McGreal R, Liu W. Lens development and crystallin gene expression. Prog Mol Biol Transl Sci. 2015;134:129-67. 
58. Cvekl A, Ashery-Padan R. The cellular and molecular mechanisms of vertebrate lens development. Development. 2014;141:4432-47.

59. Glaser T, Jepeal L, Edwards JG, et al. PAX6 gene dosage effect in a family with congenital cataracts, aniridia, anophthalmia and central nervous system defects. Nat Genet. 1994;7:463-71.

60. Hever AM, Williamson KA, van Heyningen V. Developmental malformations of the eye: the role of PAX6, SOX2 and OTX2. Clin Genet. 2006;69: 459-70.

61. Deml B, Reis LM, Lemyre E, et al. Novel mutations in PAX6, OTX2 and NDP in anophthalmia, microphthalmia and coloboma. Eur J Hum Genet. 2016;24:535-41.

62. Mauri L, Franzoni A, Scarcello M, et al. SOX2, OTX2 and PAX6 analysis in subjects with anophthalmia and microphthalmia. Eur J Med Genet. 2015;58:66-70.

63. Livne-Bar I, Pacal M, Cheung M, et al. CHX10 is required to block photoreceptor differentiation but is dispensable for progenitor proliferation in the postnatal retina. Proc Natl Acad Sci U S A. 2006; 103:4988-93

64. Ferda Percin E, Ploder LA, Yu JJ, et al. Human microphthalmia associated with mutations in the retinal homeobox gene CHX10. Nat Genet. 2000;25:397-401.

65. Bar-Yosef U, Abuelaish I, Harel T, et al. CHX10 mutations cause non-syndromic microphthalmia/anophthalmia in Arab and Jewish kindreds. Hum Genet. 2004;115:302-9.

66. Iseri SU, Wyatt AW, Nürnberg G, et al. Use of genome-wide SNP homozygosity mapping in small pedigrees to identify new mutations in VSX2 causing recessive microphthalmia and a semidominant inner retinal dystrophy. Hum Genet. 2010;128:51-60.
67. Asai-Coakwell M, French CR, Ye M, et al. Incomplete penetrance and phenotypic variability characterize GDF6-attributable oculo-skeletal phenotypes. Hum Mol Genet. 2009;18:1110-21.

68. Tassabehji M, Fang ZM, Hilton EN, et al. Mutations in GDF6 are associated with vertebral segmentation defects in Klippel-Feil syndrome. Hum Mutat. 2008;29:1017-27.

69. Iseri SU, Osborne RJ, Farrall M, et al. Seeing clearly: the dominant and recessive nature of FOXE3 in eye developmental anomalies. Hum Mutat. 2009;30:1378-86.

70. Reis L, Tyler R, Schneider A, et al. FOXE3 plays a significant role in autosomal recessive microphtalmia. Am J Med Genet A. 2010;152:582-90.

71. Ali M, Buentello-Volante B, McKibbin M, et al. Homozygous FOXE3 mutations cause non-syndromic, bilateral, total sclerocornea, aphakia, microphthalmia and optic disc coloboma. Mol Vis. 2010;16:1162-8.

72. Sibel I, Osborne R, Farrall M. Seeing clearly: the dominant and recessive nature of FOXE3 in eye developmental anomalies. Hum Mutat. 2008;30:1-9.

73. Levine AJ, Brivanlou AH. GDF3, a BMP inhibitor, regulates cell fate in stem cells and early embryos. Development. 2006;133:209-16.

74. Ye M, Berry-Wynne KM, Asai-Coakwell M, et al. Mutation of the bone morphogenetic protein GDF3 causes ocular and skeletal anomalies. Hum Mol Genet. 2010;19:287-98.

75. Cheng YC, Huang YC, Yeh $\mathrm{TH}$, et al. Deltex 1 is inhibited by the NotchHairy/E(Spl) signaling pathway and induces neuronal and glial differentiation. Neural Dev. 2015;10:1-15.

76. Zizioli D, Tiso N, Guglielmi A, et al. Knock-down of pantothenate kinase 2 severely affects the development of the nervous and vascular system inzebrafish, providing new insights into PKAN disease. Neurobiol Dis. 2016;85:35-48. 